\title{
Laser Induced Forward Transfer (LIFT) of Materials using 40 ps Pulses- Experimental and Quantitative Modelisation Study
}

\author{
Saad Al Tarazi ${ }^{*}$ Yas Al Hadeethi ${ }^{* *}$, Luca Volpe ${ }^{*}$, Luca Antonelli ${ }^{*}$, Bruno \\ Vodopivec $^{*}$, Rashida Jafer ${ }^{*}$, Marialuisa Vitobello ${ }^{* * *}$, Munawer Iqbal $^{* * * *}$, Shahid Hussain ${ }^{* * * * *}$, Dimitri Batani ${ }^{* * * * *}$ \\ *University of Milano-Bicocca, Piazza della Scienza 3, Milano, Italy \\ ${ }^{* *}$ Dept. of Physics, King Abdul Aziz University, Saudi Arabia, Jeddah 21589, P.O Box 80203 \\ ${ }^{* * *}$ European Jewellery Technology Network EJTN-GEIE \\ ${ }^{* * * *}$ Centre for High Energy Physics, University of the Punjab, Quaid-e-Azam, Campus, Lahore-Pakistan \\ ${ }^{* * * * *}$ National Tokamak Fusion Program, P. O. Box 3329, Islamabad 44000, Pakistan \\ "Centre Lasers Intenses et Applications, Université Bordeaux 1, 351, \\ Cours de la Liberation, 33405 Talence cedex, France
}

\begin{abstract}
In this paper we report the results of experiments on LIFT performed using single pulses from a mode locked (40ps pulses), frequency doubled Nd:YAG laser (energy flux $\approx 13 \mathrm{~J} / \mathrm{cm}^{2}$ at $\lambda=532 \mathrm{~nm}$ ). We studied the controlled transfer of thin films of different metallic materials to a receiving substrate. Optical and scanning electron microscopy (SEM) as well as Energy-dispersive X-ray spectroscopy (EDAX) analysis were performed, showing evidence of the production of micrometric scale patterns. One of our objectives is to investigate and develop possible applications of LIFT in jewellery industry. In order to understand the experimental results we developed a simple analytical model based on the Rankine-Hugoniot relations. Comparison between experimental and simulated results is presented.
\end{abstract}

DOI:10.2961/jlmn.2011.02.0010

Keywords: Laser induced forward transfer, picosecond laser, micrometric scale patterns

\section{Introduction}

Laser induced forward transfer (LIFT) was first demonstrated by Bohandy et al. in 1986 [1]. LIFT has the following three phases: (a) a laser pulse impinges on a donor film vaporizing a portion of it. (b) plasma expansion ejects a piece of donor film at high velocity (c) the ejected film, in the form of micro-sized clusters, bonds with the acceptor substrate. LIFT has been implemented by several research groups due to its efficiency in fabricating microstructures. Applications in micro patterning are indeed needed in integrated circuits industry, optical data storage, laser printing for organic and Polymer for optoelectronics, laser printing of biomaterials. Furthermore, LIFT can be an important technique for thin film deposition and micromachining.

Even if laser ablation starts at laser fluxes as low as several tens of $\mathrm{mJ} / \mathrm{cm}^{2}[2,3]$, laser pulses at higher fluxes (up to several $\mathrm{J} / \mathrm{cm}^{2}$ ) are needed for laser transfer. Selected works of other researchers on LIFT deposition are outlined in references [4-14].

LIFT can be compared to PLD (pulsed laser deposition).
In PLD, a laser beam of high intensity is focused on a target and an expanding coating plume is created and subsequently condenses on a substrate. Instead, LIFT is a micro printing technique, which adds mass instead of removing mass, it can be considered as inverse technique of micromachining. In particular, in the present paper, we show some preliminary results concerning the controlled transfer of thin films of different metallic materials to a receiving substrate using single pulses from a mode locked $(\tau \approx 40$ ps pulse duration), frequency doubled Nd:YAG laser. Receiving substrates were placed at a close proximity to the thin film. Optical and scanning electron microscopy (SEM) as well as EDAX analysis was performed, showing evidence of the production of micrometric scale patterns.

Our final goal was to study the transfer of precious metal to metal / crystals for possible applications in jewellery industry. LIFT is a promising technique in jewellery industry because design and manufacture requires state-of-the-art-tools. LIFT writing on rings or flat components is expected to give the level of customization 
and personalization required by the customer using compact and efficient systems. Also, while almost all previous studies focused on the use of relatively long pulses, here we made use of short laser pulses. In the field of laser ablation, it is well known that short pulse (fs and ps) may have several advantages over longer ones $[2,3]$. Therefore, in our study, we were also motivated by the idea of testing LIFT performances in the short pulse regime.

Since this is a preliminary study, we were not interested in reproducing definite patterns onto the substrate but we just studied the transfer of a foil portion roughly corresponding to the laser beam size on the target foil and studied its adhesion.

We also developed a simple physical model of LIFT at high laser intensity. The model is based on the idea that laser irradiation creates a shock wave travelling in the donor material. After shock breakout, the foil is accelerated and the donor material impinges and eventually sticks on the substrate.

The model is using Rankine-Hugoniot $(\mathrm{RH})$ relations for shock dynamics and a specific equation of state model (we used the SESAME tables [15]). The results of the model were qualitatively compared to our experimental data showing significant comparable trends.

\section{Experimental set-up}

We used single laser pulses generated from a mode locked (pulse duration $\tau=40 \mathrm{ps}$ ), frequency doubled (532 $\mathrm{nm}) \mathrm{Nd}$ :YAG laser. The system is described in ref. [16].

The maximum applied laser energy on foil was $\leq 25 \mathrm{~mJ}$. The target (thin foil) was positioned far from the best focus to get a quite large beam size (diameter $\leq 0.5 \mathrm{~mm}$ ) implying a laser flux on target $\approx 13 \mathrm{~J} / \mathrm{cm}^{2}$.

The receiving substrates were metals, semiconductors or crystals. They were placed parallel, at a close proximity to the thin film (distance of the order of $100 \mu \mathrm{m}$, in few cases at $1 \mathrm{~mm}$ ). Samples were mounted on a mechanicallycontrolled, two-axis translation stage, so to expose fresh areas of the film to each laser pulse.

All experiments were conducted in air at room temperatures. Although, irradiation under vacuum would prevent any possible role of the ambient gas, in reality already in 1988 , Bohandy et al. [4] compared results obtained in vacuum and in air and noticed how LIFT could be done equally well in air. By matter of fact, today most experimental work on LIFT is done in air. Therefore, we also chose to study LIFT processes in the conditions in which it is usually done.

Optical and scanning electron microscopy (SEM) as well as EDAX analysis was performed to the substrates, pattern of many different materials on substrates.

\section{Experimental results:}

As stated before, this is preliminary study aiming at optimising the laser parameters and the foil/substrate couple in order to improve the efficiency of LIFT (transfer yield and transfer uniformity). Therefore we performed many irradiation experiments by changing the foil thickness, the laser energy, the foil and the substrate materials.

In the first set of experiments, we changed the substrate and maintained a fixed foil material and thickness (either $\mathrm{A}$ at $4 \mu \mathrm{m}$ or $\mathrm{Au}$ at $1 \mu \mathrm{m}$ ). Results are summarised in Table 1. Table 1 First set of experiments, changing the substrate:

$\begin{array}{ll}\text { (a) transfer of } 4 \mu \mathrm{m} \text { foils of } \mathrm{Al} & \text { (b) } 1 \mu \mathrm{m} \text { of } \mathrm{Au}\end{array}$

\begin{tabular}{|c|c|c|c|}
\hline \multicolumn{4}{|c|}{$\begin{array}{l}\text { SubstrateRemarks/SubstrateRemarks/ } \\
\text { Material Adhesion Material Adhesion }\end{array}$} \\
\hline $\mathrm{Cu}$ & good & $\mathrm{Cu}$ & good \\
\hline $\mathrm{Si}$ & good & $\mathrm{Si}$ & good \\
\hline $\mathrm{Ni}$ & good & Agate & good \\
\hline $\mathrm{Pb}$ & poor & $\mathrm{SiO} 2$ & good \\
\hline $\mathrm{Zn}$ & poor & $\mathrm{Zn}$ & good \\
\hline $\mathrm{Pd}$ & poor & Quartz & Nothing \\
\hline
\end{tabular}

The second set of experiments was designed to investigate the effect of foil material. Results are summarised in table 2 .

Table 2 Second set of experiments: changing the foil material (4 $\mu \mathrm{m}$ thickness). Comparison of transfer on Silver and Glass substrate.

\begin{tabular}{ccc}
\hline $\begin{array}{c}\text { Foil } \\
\text { Material }\end{array}$ & $\begin{array}{c}\text { Substrate } \\
\text { Material }\end{array}$ & $\begin{array}{c}\text { Remarks/ } \\
\text { Adhesion }\end{array}$ \\
\hline $\mathrm{Sn}$ & Silver & good \\
$\mathrm{Au}$ & " & good \\
$\mathrm{Ti}$ & " & poor \\
$\mathrm{Al}$ & $\mathrm{SiO} 2$ & good \\
$\mathrm{Sn}$ & “ & poor \\
$\mathrm{Au}$ & “ & Poor \\
$\mathrm{Cu}$ & “ & Poor \\
\hline
\end{tabular}

Finally, in the third set of experiments we changed the foil thickness (either 1 or $4 \mu \mathrm{m}$ ). Results are summarised in Table 3. Although here we changed the substrate too, which does not allow drawing definite conclusions (two parameters being changed at the same time), nevertheless practically in all cases, the transfer was better with $1 \mu \mathrm{m}$ foils than with $4 \mu \mathrm{m}$ foils.

Table 3 Third set of experiments: changing foil thickness

\begin{tabular}{cccc}
\hline $\begin{array}{c}\text { Foil } \\
\text { Material }\end{array}$ & $\begin{array}{c}\text { Foil Thickness } \\
(\mu \mathrm{m})\end{array}$ & $\begin{array}{c}\text { Substrate } \\
\text { Material }\end{array}$ & $\begin{array}{c}\text { Remarks/ } \\
\text { Adhesion }\end{array}$ \\
\hline $\mathrm{Au}$ & 1 & $\mathrm{Cu}$ & good \\
" & " & $\mathrm{Si}$ & good \\
“ & " & $\mathrm{Pb}$ & poor \\
“ & 4 & $\mathrm{Silver}$ & good \\
“ & “ & quartz & nothing \\
“ & “ & $\mathrm{SiO} 2$ & poor \\
$\mathrm{Cu}$ & 1 & $\mathrm{Sn}$ & good \\
“ & 4 & $\mathrm{SiO} 2$ & poor \\
\hline
\end{tabular}

In a fourth set of experiments, we investigated the effect of laser pulse energy by irradiating the same samples with $2 \mathrm{~mJ}$ laser pulses. In all cases, results at reduced 
energy were worse than those using $20 \mathrm{~mJ}$ laser pulses, especially in terms of adhesion. Of course, many more energy values could have been tested but this was not really the goal of this preliminary work. Here the variation of laser energy was not intended to explore the full parameter space but rather just to try to get a "working" point where we could perform meaningful experiments.

Optical microscope images of Al deposited on Agate are shown in fig.1. SEM image at the deposited Al on Agate, as well as the EDAX spectrum are shown in fig 2.
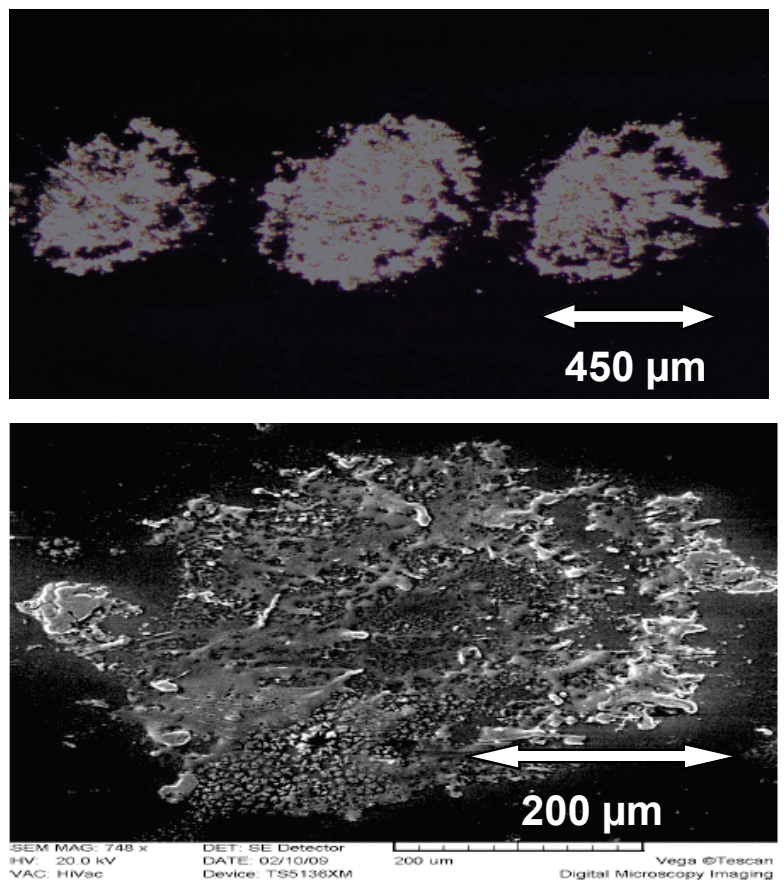

Fig. 1 Optical microscope image (top) and SEM image (bottom) of the deposited Al on Agate.

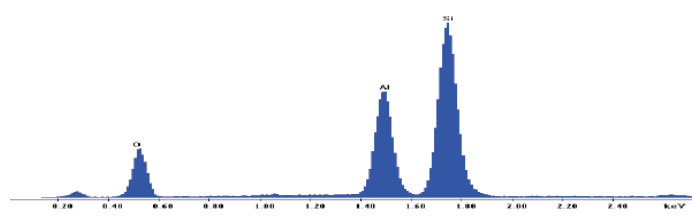

Fig. 2 EDAX spectrum showing quantitative analysis of the Agate with evidence of $\mathrm{Al}$ deposits

In particular, it was observed with the naked eye that forward transfer of $\mathrm{Al}$ was induced and $\mathrm{Al}$ deposited on the Agate surface. Adhesion of the deposited film was very good. It was not possible to remove it from the Agate substrate even when applying a sticking tape (the so-called "tape test" is simple but largely used to test the adhesion of deposited film [17, 18]). It is a method for evaluating the adhesion of a coating to a substrate. A sticking tape is tightly applied to an area of the coating. Adhesion is considered to be adequate if coating is not pulled off when the tape is suddenly and very quickly removed. It is proved to be a simple and reliable standard test that can measure in a reproducible manner the adhesive strength of a deposited coating to a substrate.

Gold was found to be easily transferred to the silver substrate with high adhesion. Optical microscopy and SEM images and the EDAX spectrum of the produced deposit are shown in fig. 3 and fig. 4 respectively. Figure 5 shows instead the transfer of $\mathrm{Cu}$ on $\mathrm{Ag}$, again with a high adhesion. It's EDAX spectrum is shown in fig 6. However, we were not able to transfer $\mathrm{Sn}$ or Fe to Ag. Interestingly, the measured areas of the deposited Al on Agate, Au on Ag and $\mathrm{Cu}$ on $\mathrm{Ag}$ were not comparable.
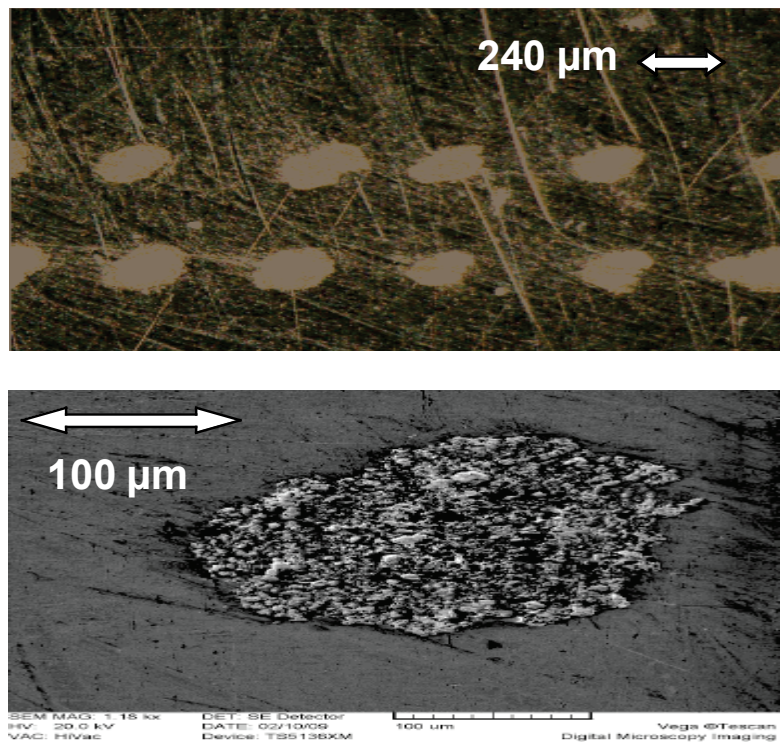

Fig. 3 Optical (top) and SEM (bottom) image showing $\mathrm{Au}$ deposited on $\mathrm{Ag}$

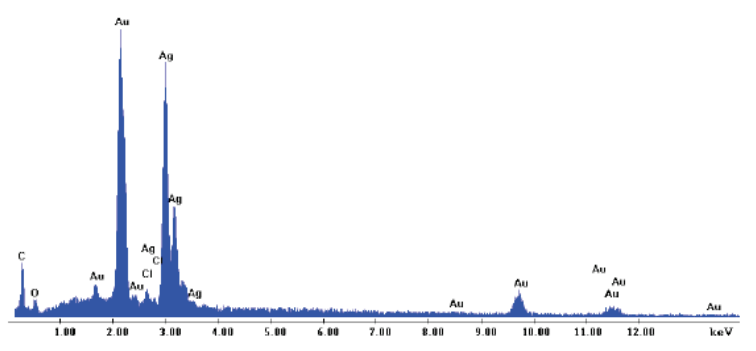

Fig. 4 EDAX spectrum of Au deposited on $\mathrm{Ag}$
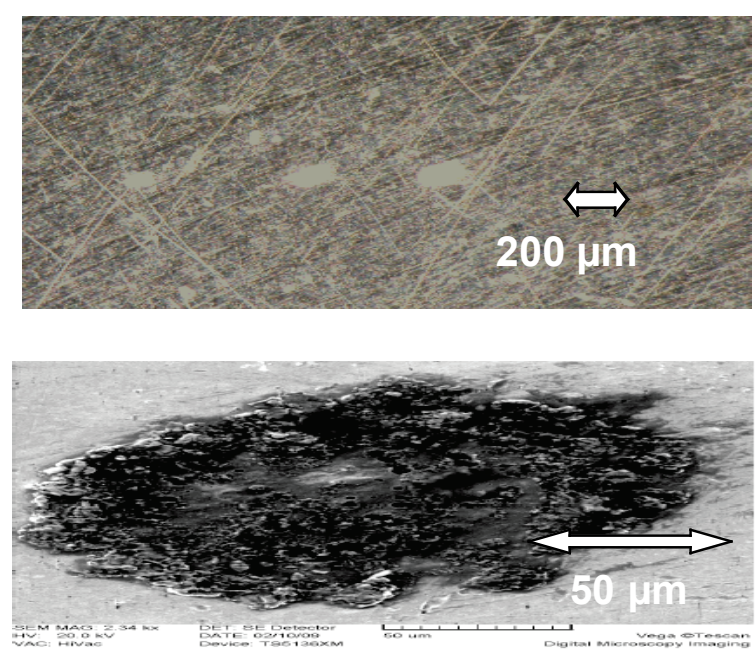
Fig. 5 Optical (top) and SEM image (bottom) of $\mathrm{Cu}$ deposited on $\mathrm{Ag}$

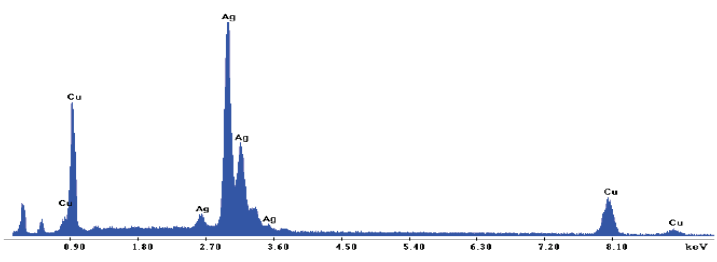

Fig. 6 EDAX spectrum of $\mathrm{Cu}$ deposited on $\mathrm{Ag}$ on $\mathrm{Ag}$

Finally, we also noticed that $\mathrm{Al}$ of $4 \mu \mathrm{m}$ was successfully deposited on Si (see fig. 7). It is EDAX spectrum is shown in fig 8 .
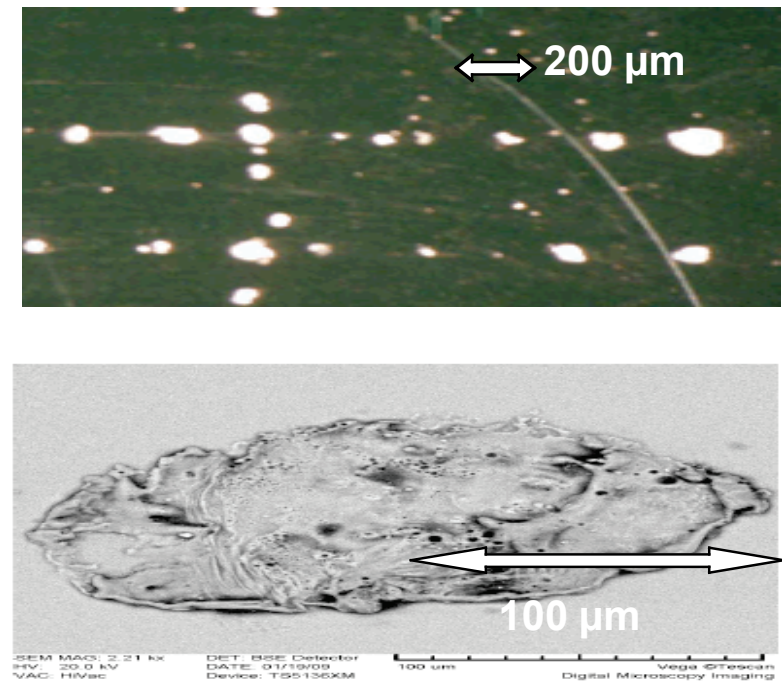

Fig. 7 Optical (top) and SEM image (bottom) of Al deposited on $\mathrm{Si}$

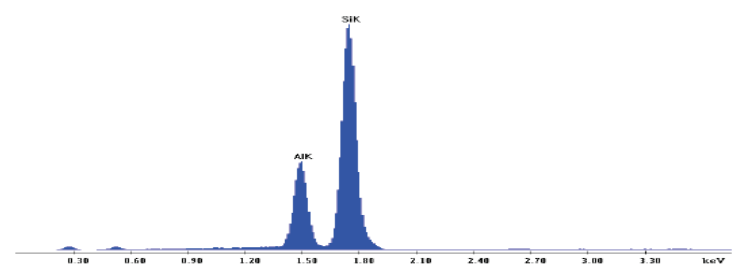

Fig. 8 EDAX spectrum of $\mathrm{Al}$ deposited on $\mathrm{Si}$

In contrast, the irradiation of $5 \mu \mathrm{m} \mathrm{Au}$ foil in close contact to Malachite showed no deposition on Malachite. Similar results were obtained when using $\mathrm{Sn}$ and $\mathrm{Cu}$ foils instead of $\mathrm{Au}$ foil. Again, we notice how this work is preliminary and will continue. Due to the many parameters playing a role in LIFT, it is indeed difficult to get a full picture of the phenomenon and optimize it over all such experimental parameters. However, this result seems encouraging about LIFT technique as a possible approach satisfying the needs of jewellery industry.

\section{A model for LIFT}

In order to gain some general understanding of LIFT in the ps laser pulse duration regime, it is important to try to physically model our results. As just explained before LIFT takes place in 3 steps [2] namely: (a) a laser pulse impinges on a donor film vaporizing a portion of it. (b) plasma expansion ejects a piece of donor film at high velocity (c) the ejected film, in the form of micro-sized clusters, bonds with the acceptor substrate (see Fig. 9)

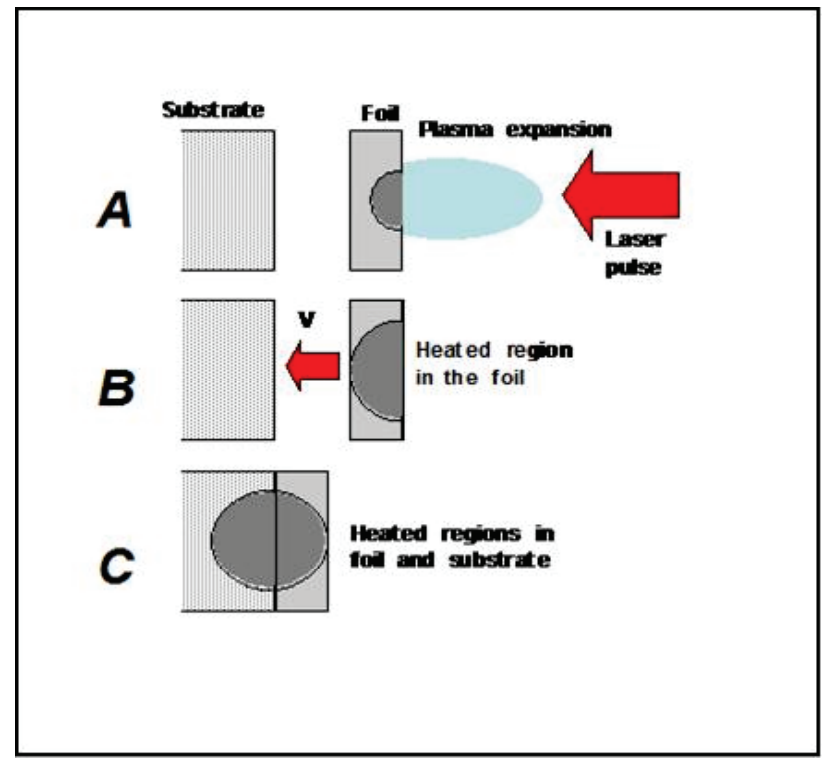

Fig. 9 Different phases of LIFT: up) ablation. The laser pulse vaporizes the surface layer causing vaporization and plasma expansion in vacuum and the propagation of a heat wave in the material; centre) motion at high velocity (V) of the film; c) impact with the substrate and creation of heated regions in foil and substrate.

The process was initially described by Bohandy et al. [1] as the propagation of a non-linear heat wave in the material. According to the authors, the necessary conditions for producing a good LIFT were that the heat wave was so sufficient to produce the melting of the foil. Clearly this model may work at relatively low laser intensities but fall in the ps regime where higher intensities are used and then the heat wave changes to a laser-driven shock. Moreover, in their model they completely neglected the phases of motion and impact between the foil and substrate, which are also essential. Indeed, several experimental results, including ours, show that the same foil (material and thickness) may adhere well to one substrate and in a worse way to another, thereby pointing to the role of the foil/substrate couple.

Let's notice that at the flux we used $\left(\approx 13 \mathrm{~J} / \mathrm{cm}^{2}\right)$, the laser intensity on target is of the order of $3 \times 10^{11} \mathrm{~W} / \mathrm{cm}^{2}$ and the nonlinear heat wave really becomes a shock wave of pressure $\approx 0.3$ Mbar travelling in the foil material. At the time of shock breakout, i.e. when the shock reaches the target rear side, the material relaxes and a decompression wave travels back into the material (all these process are for instance described in [19]). Now depending on the shock pressure, the material may reach a temperature either above the boiling point of the material (causing vaporization of the rear side) or above the melting point (causing fusion of the material). Finally, the target is set in motion with velocity $\mathrm{V}$ $=\mathrm{P} \tau / \rho \mathrm{d}$ (where $\rho$ and $\mathrm{d}$ are density and thickness of the foil respectively and $\mathrm{P}$ is the shock pressure, (i.e. the ablation, 
pressure) and impacts the substrate. Again, at impact, a shock is generated in both the substrate and foil, as described in [20].

The dynamic of the high intensity shock wave can be described using the Rankine-Hugoniot relations which represent mass, momentum and energy conservation across the shock front i.e. a system of three equations with six independent physical variables (pressure $\mathrm{P}$, internal energy, $U$, fluid velocity $u$, shock wave velocity $D$, solid and shocked material density $(\rho, \rho$ '). The RH relations in the high pressure limit $\mathrm{P}>>\mathrm{P}_{0}$ (where $\mathrm{P}_{0}$ is the initial pressure) are the following

$$
\begin{aligned}
& D \rho=(D-u) \rho^{\prime} \\
& P=\rho D u \\
& U-U_{0}=P u-\frac{1}{2} u^{2}
\end{aligned}
$$

This system brings to well known formula where one use the perfect gas form EOS (equation of state). However, in order to put better description of material behaviour we used the SESAME EOS developed at Los Alamos[15]. From those tables we can obtain the relations between all the above mentioned relevant physical observables. We are interested in estimating these physical observables during the relevant phases of our experiments, which are,: (a) laserfoil interaction. (c) foil-substrate interaction. The initial experimental parameters are: the laser parameters (wavelength, Intensity, pulse duration) and the initial density of both the foil and the substrate materials.

To estimate the "expected" pressure on foil surface we used the following well known relation between the laser parameters and the induced pressure on the irradiated foil [21]:

$$
P(M b a r)=8.6\left(\frac{I\left(W / \mathrm{cm}^{2}\right)}{10^{14}}\right)^{2 / 3} \lambda^{-2 / 3}\left(\frac{A}{2 z}\right)^{1 / 3}
$$

From this using RH relations and SESAME EOS we then deduces all the others quantities. The ablation pressure induces a velocity on to the foil, which can be estimated using the Newton's second law.

$$
v_{f}=\frac{p \tau}{\rho d^{\prime}}
$$

Here d' (the remaining thickness after ablation) differs from the initial foil thickness $d$ because part of its mass is removed (ablated from the foil following laser interaction):

$$
\left.\begin{array}{l}
d^{\prime}=d-d_{a b l} ; \quad d_{a b l}=\frac{m \tau}{\rho} ; \\
\dot{m}\left(\frac{\mathrm{Kg}}{\mathrm{cm}^{2} s}\right)=150\left(\frac{I\left(W / \mathrm{cm}^{2}\right)}{10^{14}}\right)^{1 / 3} \lambda^{-4 / 3}
\end{array}\right\}
$$

Here $\dot{m}$ is the mass ablation rate and $d_{a b l}$ is the ablation depth. However for all cases of interest $d_{a b l} \ll d$, so that the difference is negligible. To obtain the induced pressure on substrate (due to the foil impact ) we started from the relation between shock and fluid velocities, which can be obtained using SESAME tables. This is usually represented by the linear relation:

$$
D=\Gamma_{i} u+\beta_{i}
$$

here $\Gamma$ and $\beta$ are coefficients depending on the material (in particular $\beta$ is the acoustic velocity in the shocked material). The above relation can be inserted in eq. 2 to obtain the pressure as a function of the fluid velocity only, for any material " $i$ " (the so called shock polar).(here I can either represent the foil or the substrate)

$$
P_{i}=\rho_{i} u\left(\Gamma_{i} u+\beta_{i}\right)
$$

The shock polar relation can be written for the thin film and for the substrate in the substrate reference-frame.

$$
\begin{aligned}
& P_{f}=\rho_{f}\left|u-v_{f}\right|\left[\Gamma_{f}\left|u-v_{f}\right|+\beta_{f}\right] \\
& P_{s}=\rho_{s} u\left(\Gamma_{s} u+\beta_{s}\right)
\end{aligned}
$$

where $v_{f}$ is the velocity of the foil, and $\rho_{f}, \rho_{\mathrm{s}}$ represent respectively foil and substrate initial densities.

We assume that during the impact between foil and substrate, the pressure and fluid velocity on the foil and on the substrate surfaces are the same. This is due to the momentum conservation laws. The fluid velocity $\left(u=u_{f}=u_{s}\right)$ and the pressure $\left(\mathrm{P}=\mathrm{P}_{\mathrm{f}}=\mathrm{P}_{\mathrm{s}}\right)$ at the moment of the impact can then be obtained from eqs. (8) and (9).

$$
\begin{aligned}
& u=f\left(R, a, b, c, v_{f}\right) \approx f^{\prime}(R, a, b, c) v_{f} \\
& P=F\left(R, a, b, c, v_{f}\right) \approx F^{\prime}(R, a, b, c) v_{f}^{2}
\end{aligned}
$$

$$
\begin{aligned}
& \text { where } \\
& \left.\qquad \begin{array}{r}
\mathrm{R}=\frac{\rho_{f}}{\rho_{s}} ; \quad \mathrm{a}=\frac{\Gamma_{f}}{\beta_{f}} ; \\
\mathrm{b}=\frac{\beta_{s}}{\beta_{f}} ; \quad \mathrm{c}=\Gamma_{s} / \Gamma_{f}
\end{array}\right\}
\end{aligned}
$$

The functions $\mathrm{f}$ and $\mathrm{F}$ are shown in the appendix of this paper. The free gas limit is also shown. The parameters in (13) can be estimated using equation of state EOS contained in SESAME tables; in particular we get the induced pressure on substrate due to the collision with the moving foil. Tables 4 and 5 show the theoretical estimations for different materials, based on our analytical model and using the SESAME tables. 
Table 4: theoretical estimation of laser induced pressure (col. 2, eq. 4), velocity of the foil due to the ablation pressure (col. 3, eq. 5) and the reached temperatures on foil surface (col. 4, SESAME). In column 5 , the foil temperatures compared to the material melting point $\left(\mathrm{T}_{\mathrm{M}}\right)$ is shown.

\begin{tabular}{ccccc}
\hline Foil & $\mathrm{P}($ Mbar $)$ & $\mathrm{v}_{0}(\mathrm{~m} / \mathrm{s})$ & $\mathrm{T}\left(\mathrm{C}^{\mathrm{O}}\right)$ & $\mathrm{T}_{\text {foil }} / \mathrm{T}_{\mathrm{M}}$ \\
\hline $\mathrm{Al}(1 \mu \mathrm{m})$ & $\sim 0.29$ & $\sim 424.4$ & $\sim 315$ & $\sim 0.62$ \\
$\mathrm{Al}(4 \mu \mathrm{m})$ & $\sim 0.29$ & $\sim 104.0$ & $\sim 315$ & $\sim 0.62$ \\
$\mathrm{Cu}(1 \mu \mathrm{m})$ & $\sim 0.30$ & $\sim 131.4$ & $\sim 1329$ & $\sim 1.15$ \\
$\mathrm{Cu}(4 \mu \mathrm{m})$ & $\sim 0.30$ & $\sim 32.60$ & $\sim 1329$ & $\sim 1.15$ \\
$\mathrm{Au}(1 \mu \mathrm{m})$ & $\sim 0.31$ & $\sim 63.30$ & $\sim 267$ & $\sim 0.39$ \\
$\mathrm{Au}(4 \mu \mathrm{m})$ & $\sim 0.31$ & $\sim 15.80$ & $\sim 267$ & $\sim 0.39$ \\
\hline
\end{tabular}

Table 5 Theoretical estimation of the foil velocity due to the ablation pressure (col. 2, eq. 5), foil collision induced pressure on substrate (col. 3, eq. 12), the reached temperatures on foil surface during the collision (col. 4 SESAME), and the reached temperatures on substrate surface during the collision (col. 5 SESAME). In columns 6 and 7 the temperatures compared to the material melting point $\left(\mathrm{T}_{\mathrm{M}}\right)$ are shown.

\begin{tabular}{lccccc}
\hline Foil/Substrate & $\begin{array}{c}\mathrm{v}_{0} \\
(\mathrm{~m} / \mathrm{s})\end{array}$ & $\begin{array}{c}\mathrm{P}_{\text {sub }} \\
(\mathrm{kbar})\end{array}$ & $\begin{array}{c}\mathrm{T}_{\text {foil }} \\
\left(\mathrm{C}^{\circ}\right)\end{array}$ & $\begin{array}{c}\mathrm{T}_{\text {sub }} \\
\left(\mathrm{C}^{\circ}\right)\end{array}$ & $\mathrm{T}_{\text {foil }} / \mathrm{T}_{\mathrm{M}} \mathrm{T}_{\text {sub }} / \mathrm{T}_{\mathrm{M}}$ \\
\hline $\mathrm{Al}(1 \mu \mathrm{m})-\mathrm{Cu}$ & $\sim 424$ & $\sim 44$ & $\sim 27$ & $\sim 27$ & $\sim 0.321 \sim 0.230$ \\
$\mathrm{Al}(4 \mu \mathrm{m})-\mathrm{Cu}$ & $\sim 104$ & $\sim 10$ & $\sim 27$ & $\sim 57$ & $\sim 0.321 \sim 0.234$ \\
$\mathrm{Cu}(1 \mu \mathrm{m})-\mathrm{Al}$ & $\sim 131.4$ & $\sim 10$ & $\sim 57$ & $\sim 27$ & $\sim 0.353 \sim 0.289$ \\
$\mathrm{Cu}(4 \mu \mathrm{m})-\mathrm{Al}$ & $\sim 32.6$ & $\sim 2.6$ & $\sim 87$ & $\sim 27$ & $\sim 0.386 \sim 0.300$ \\
$\mathrm{Au}(1 \mu \mathrm{m})-\mathrm{Cu}$ & $\sim 63.3$ & $\sim 11$ & $\sim 57$ & $\sim 57$ & $\sim 0.353 \sim 0.320$ \\
$\mathrm{Au}(4 \mu \mathrm{m})-\mathrm{Cu}$ & $\sim 15.0$ & $\sim 2.4$ & $\sim 27$ & $\sim 87$ & $\sim 0.321 \sim 0.256$ \\
\hline
\end{tabular}

The model suggests that the ablation-induced foil velocity and the reached temperature on substrate have strong influence on the LIFT processes. This compares qualitatively well with our experimental results, as an example of good adhesion (see experimental results in Table1.a) occur always with thin aluminium foil which is characterized by the highest foil velocity (line 1 Tables 3,4) We can argue also that the initial laser parameters influence the final foil velocity only, while the physical state of the foil-substrate system is foil velocity dependent only (see eq.12). The temperature on foil depends on the laser parameters while the temperature on substrate during the foil-substrate interaction depends on the foil velocity tuned by the materials proprieties then the model allows playing with the material properties in order to improve the LIFT performance. It is important to note that from the experimental results, $\mathrm{Cu}$ seems to be the best substrate material. This behaviour cannot be explained by our model, which involve hydrodynamic variables only. Possibly this could be due to the high thermal conductivity of the $\mathrm{Cu}$ material. Finally our model should allow for an optimization of LIFT experiment in that i) one should maximize foil velocity and pressure (according to eqs. 4 and
5) and ii) one should then maximize the highest pressure and temperature on foil and substrate on impact.

\section{Conclusions}

SEM and EDAX analysis of our experimental results show that we could realize a controlled transfer of thin films of several materials to receiving substrates using single laser pulses. At our irradiation flux $\approx 13 \mathrm{~J} / \mathrm{cm}^{2}$ we observed how both the laser (pulse energy) and the target parameters significantly influence the process. In particular, it is possible to have good adhesion of metals on crystals ( $\mathrm{Al}$ on Agate) but also of precious metals onto other precious metals (Au on Ag). These results seem encouraging about LIFT technique as a possible tool in jewellery industry. We also developed a modellisation of LIFT, which qualitatively explains our experimental results. In particular in agreements with experimental results, $1 \mu \mathrm{m}$ foils are accelerated more effectively and impact at higher speed onto the substrate. Also at reduced energy both the shock is weaker (possibly producing a temperature below the melting point) and the velocity imparted to the foil is lower. We started from the relation between shock and fluid velocities, which was obtained using the EOS SESAME. Our model shows that the ablation induced foil velocity and the reached temperature on substrate influences the LIFT processes more than the other parameters. Finally, we show that the initial laser parameters influence the final foil velocity only, while the physical state of the foil-substrate system is foil velocity dependent only (see eq.12). Moreover we can play with the material proprieties in order to improve the LIFT performance.

\section{Appendix}

We start from eqs. $(9,10)$ and the following A1 and A2:

$$
\begin{aligned}
& P_{f}=\rho_{f}\left|u-v_{f}\right|\left[\Gamma_{f}\left|u-v_{f}\right|+\beta_{f}\right] \\
& P_{s}=\rho_{s} u\left(\Gamma_{s} u+\beta_{s}\right)
\end{aligned}
$$

Since $\mathrm{u}<\mathrm{v}_{\mathrm{f}}$ then $\left|\mathrm{u}-\mathrm{v}_{\mathrm{f}}\right|=\mathrm{v}_{\mathrm{f}}-\mathrm{u}$.

At the impact moment the pressure and the fluid velocities on the foil and substrate surface are the same then $A_{1}$ and $\mathrm{A}_{2}$ gives:

$$
A u^{2}+B u+C \Rightarrow u=\frac{-B-\sqrt{B^{2}-4 A C}}{2 A}
$$

Where

$$
\begin{aligned}
& \mathrm{A}=\mathrm{a}_{\mathrm{f}}\left(\mathrm{R}_{\mathrm{f}, s}-\mathrm{c}_{\mathrm{f}, s}\right) ; B=-\left[\mathrm{b}_{\mathrm{f}, s}+\mathrm{R}_{\mathrm{f}, 3}\left(1+\mathrm{a}_{\mathrm{f}}\right)\right] ; \\
& \mathrm{C}=\mathrm{v}_{\mathrm{f}} \mathrm{R}_{\mathrm{f}, s}\left(1+\mathrm{a}_{\mathrm{f}} \mathrm{v}_{\mathrm{f}}\right) \text {; }
\end{aligned}
$$




$$
\left.\begin{array}{l}
R_{f, s}=\frac{\rho_{f}}{\rho_{s}} ; \quad a_{f}=\frac{i_{f}}{\beta_{f}} ; \\
b_{f, s}=\beta_{s} / \beta_{f} ; \quad c_{f, s}=\Gamma_{s} / \Gamma_{f}
\end{array}\right\}
$$

By inserting the solution of eq. A3 into A2 we can obtain the final pressure on foil-substrate surface. As an example let us assume the free gas approximation then $\beta_{\mathrm{f}}=\beta_{\mathrm{s}}=0$ and $\Gamma_{\mathrm{f}}=\Gamma_{\mathrm{s}}=\Gamma=(\gamma+1) / 2$. The fluid velocity depends only on the relation between the material densities:

$$
u=\frac{\sqrt{R_{f, s}}}{\sqrt{R_{f, s}+1}} v_{f}
$$

If $\mathrm{R}=1$, then

$$
u=\frac{1}{2} v_{f}
$$

Assuming the same material for foil and substrate $(\mathrm{R}=1)$, the fluid velocity is found to be half of the foil velocity as in the inelastic collision between two objects with the same mass. Fig.A1 shows the final pressure on substrate as a function of the foil velocity for the general case compared with the free gas approximation.

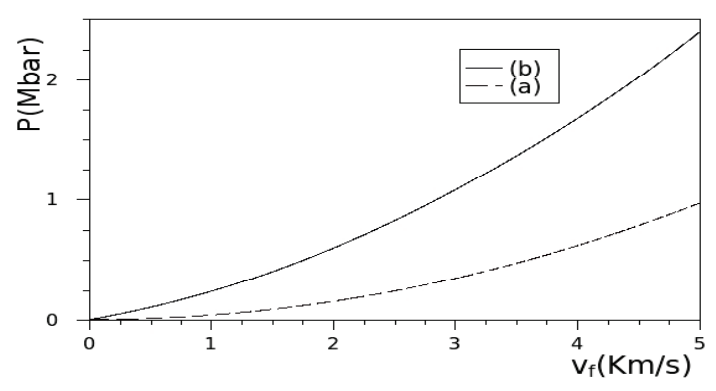

Fig. A1 Pressure on substrate as a function of the foil velocity (eq.12 or A2) Gold on Copper (a) general case (b) free gas approximation.

\section{Acknowledgments:}

SAT acknowledges the support of the and European Jewellery Technology Network (EJTN-GEIE). YAH acknowledges the support of the ICTP-TRIL Programme.

\section{References:}

[1] J. Bohandy, B. F. Kim, and F. J. Adrian: J. Appl. Phys., A53, (1991), 241.

[2] S. Nolte, C. Momma, H. Jacobs, A. Tünnermann, B.N. Chichkov, B. Wollegehausen and H. Welling J. Opt. Soc. Am. B 14 (1997), p. 2716.

[3] D.Batani: "Laser Ablation and Laser Induced Plasmas for Nanomachining and Material Analysis" in "Functionalized Nanoscale Materials, Devices, and Systems for Chem.-Bio Sensors, Photonics, and Energy Generation and Storage" June 4-15, 2007, Sinaia, Romania (2007)

[4] J. Bohandy, B. F. Kim, F. J. Adrian, and A. N. Jette: J. Appl. Phy., 63, (1988), 1158.

[5] I. Zergioti, S. Mailis, N.A. Vainos, C. Fotakis, S. Chen, and C. P. Grigoropoulos: Applied Surface Science, 127, (1998), 601.

[6] D. P. Banks, Ch. Grivas, J. D. Mills, and R. W. Eason Appl. Phys. Lett., 89, (2006), 193107.

[7] N. T. Kattamis, P. E. Purnick, R. Weiss and C. B. Arnold: Appl. Phys. Lett. 91, (2007), 171120.

[8] K. D. Kyrkis, A. A. Andreadakia, D.G. Papazogloub, and I. Zergioti, Recent advances in laser processing of materials, Chp.7 edited by Jacques Perrière, Eric Millon, Eric Fogarassy, Elsevier Ltd.2006

[9] E .Fogarassy, C. Fuchs, F. Kerherve, S. de Unamuno, and J. Perriere: Journal of Materials Research, 4, (1989), 1082.

[10] E. Fogarassy, C. Fuchs, F. Kerherve, S. Hauchecorne, and J. Perriere: J. Appl. Phys., 66, (1989), 457.

[11] E. Fogarassy, C. Fuchs, S. de Unamuno, J. Perriere, and F. Kerherve: Materials and Manufacturing Processes, 7, (1992), 31.

[12] H. Yamadi, T. Sano, T. Nakayama, and I. Miyamota: Applied Surface Science, 197, (2002), 411.

[13] Z. Kantor, Z. Toth, and T. Szorènyi: Applied Surface Science, 86, (1995), 196.

[14] R. Fardela, M. Nagel, F. Nuesch, Th. Lippert, and A.Wokaun, Applied Surface Science, 254, (2007), 1322.

[15]http://t1web.lanl.gov/doc/SESAME_3Ddatabase_1992. html

[16] A. Faenov, A. Magunov, T. Pikuz, D. Batani, G. Lucchini, F. Canova, and M. Piselli: Laser and Particle Beams, 22, (2004), 373.

[17] A. Pique', D. B. Chrisey, J. M. Fitz-Gerald, and R. A. McGill, R. C. Y. Auyeung and H. D. Wu, S. Lakeou,,Viet Nguyen, R. Chung, M. Duignan: J. Mater. Res., 15, (2000), 1872.

[18] J. M. Fitz-Gerald, D. B. Chrisey, A. Piqu, R. C. Y. Auyeung, R. Mohdi, H. D. Young, H. D. Wu, S. Lakeou, and, R. Chung: Mat. Res. Soc. Symp. Proc. Vol. 625, (2000), 99.

[19] D. Batani, A. Balducci, D. Beretta, A. Bernardinello, Th. Lower, M. Koenig, A. Benuzzi, B. Faral, and T.Hall: Phys. Rev. B, 61, (2000), 9287.

[20] R. Fabbro, B. Faral, J. Virmont, F. Cottet, and J. P. Romain: Phys. Fluids B, 1, (1989), 644.

[21] R. Fabbro, B. Faral, J. Virmont, F. Cottet, and J. P. Romain: Phys. Fluids, 28, (1985), 11.

(Received: January 20, 2011, Accepted: July 11, 2011) 